doi: 10.2306/scienceasia1513-1874.2014.40.384

\title{
Pollen viability, germination, and seed setting of Nelumbo nucifera
}

\author{
Akhom Khatfan $^{\mathrm{a}}$, Zuo Li ${ }^{\mathrm{b}}$, Long-Qing Chen ${ }^{\mathrm{c}}$, Nopadol Riablershirun ${ }^{\mathrm{a}}$, Vithaya Sathornviriyapong ${ }^{\mathrm{d}}$, \\ Niran Juntawong ${ }^{\mathrm{a}, \mathrm{e}, *}$ \\ a Department of Botany, Faculty of Science, Kasetsart University, Bangkok 10900 Thailand \\ b Guangdong Key Labs of Ornamental Plant Germplasm Innovation and Utilization, \\ Floricultural Research Institute, Guangdong Academy of Agricultural Sciences, Guangzhou 510640, China \\ c Key Laboratory of Horticultural Plant Biology, College of Horticulture and Forestry Sciences, \\ Huazhong Agricultural University, Wuhan 430070, China \\ d Department of Horticulture, Faculty of Agriculture, Kasetsart University, Bangkok 10900 Thailand \\ e Centre for Advanced Studies in Tropical Natural Resources, \\ National Research University-Kasetsart University (CASTNAR, NRU-KU), Bangkok 10900 Thailand
}

*Corresponding author, e-mail: fscinrj@ku.ac.th

Received $10 \mathrm{Jul} 2013$

Accepted 12 Nov 2014

ABSTRACT: In tropical countries, low seed setting is a major problem when cultivating lotus (Nelumbo nucifera Gaertn.). This study determined seed setting in six wild lotus cultivars: Sai Rung (SR), Sam Roi Yot (SY), Klong Yong, Puttha Monthon (PM), Rachine (RC), and Nakhon Sawan (NW). In nature, the seed-setting rates range from 52-78\%. From a stigma removal study, only a 53\% seed-setting rate by self-pollination was recorded in the SR cultivar. This result was similar to the seed setting of self-pollinated PM, although high viability of PM pollen from day 2 full bloom flowers was observed. Self-incompatibility was studied in RC and NW cultivars. The indices of self-incompatibility of RC and NW were both $96 \%$ indicating that self-incompatibly affects low seed setting in these two cultivars. The results showed that the low seed-setting rate also came from seed abortion. A high value of self-incompatibility was observed in RC and NW cultivars, but not in the other cultivars studied.

KEYWORDS: sacred lotus, pollination, self-incompatibility, abortion

\section{INTRODUCTION}

Lotus (Nelumbo nucifera Gaertn.) is an aquatic plant which is widely grown in East and South-East Asian countries where it has been used for food and medicine for millennia. The seeds are ingredients in several Thai dishes. The petals, stamen, torus, and embryo are used in traditional medicines due to their potential for cooling and healing. The flowers are also decorative ${ }^{1,2}$.

Low seed setting is a problem in growing lotus ${ }^{3,4}$. Seed setting is limited by pollination mechanisms, such as the abundance of pollinators ${ }^{3,5}$ and pollen viability $^{4,6}$. As lotus pollinator in tropical areas are abundant, pollen viability is the next factor to be considered as a cause of low seed setting. Pollen viability corresponds to the ability of pollen to transfer the male gamete to the embryo $\mathrm{sac}^{7}$. A low pollen viability reduces the germination rate and lowers the seed setting rate ${ }^{8,9}$. Apart from pollen viability, stigma receptivity, and self-incompatibility are also factors that could affect the seed-setting rate ${ }^{10,11}$.

Self-incompatibility is caused by the interaction between pollen and stigma containing a similar genetic pattern; this is a mechanism that prevents inbreeding in plants ${ }^{10,11}$. The mechanism often coexists with protogyny, where the stigma develops faster than the anther, or with protandry, where the anther develops faster than the stigma ${ }^{12-16}$. This sequential hermaphroditism of dichogamous type of flower ensures that the stigma receives pollen from other flowers rather than its own. Out-crossing promotes seed setting in many plant species ${ }^{14}$ but has not been reported in lotus.

Three forms of self-incompatibility ${ }^{17}$ were considered in this study. Sporophytic self-incompatibility occurs where the phenotype of the pollen is determined by the pollen coat which is the sporophytic or diploid part ${ }^{18}$. In this form of self-incompatibility, pollen germination is inhibited as soon as the pollen falls onto the stigma. Gametophytic selfincompatibility occurs where the phenotype of the 

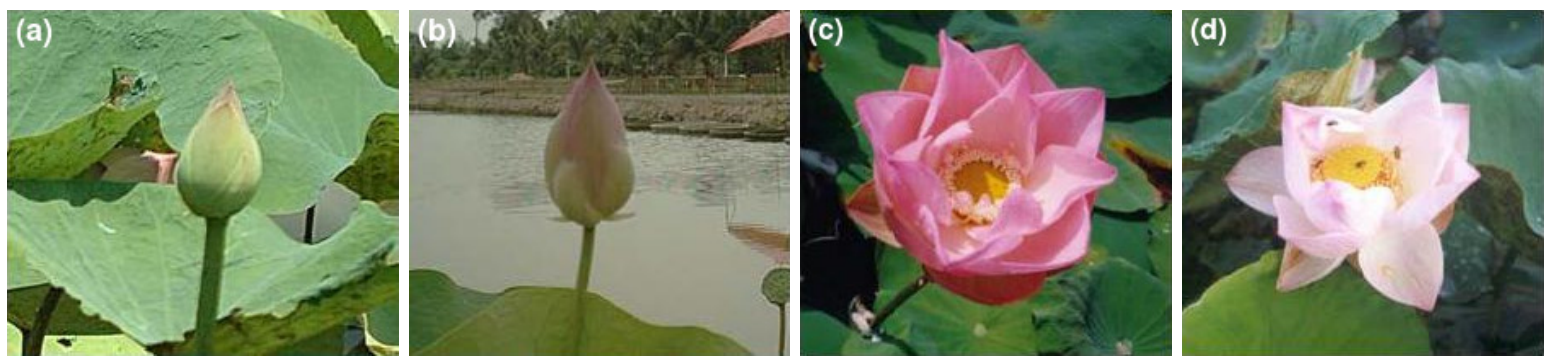

Fig. 1 Different blooming stages of flowers at (a) 2 days pre-bloom, (b) 1 day pre-bloom, (c) day 1 of full bloom, and (d) day 2 of full bloom.

pollen is determined by its own gametophytic haploid genotype. Self-pollen can germinate but the pollen is shortly inhibited by stigma tissue. Cryptic selfincompatibility occurs where stigmatic or stylar tissue promotes germination of cross pollen grains more than self ones ${ }^{15}$

Not only does self-incompatibility affect seed setting but once fertilization has occurred, post embryonic suppression also influences seed formation. If self-fertilization occurs, the embryo development will be further inhibited by this suppression and the seed becomes aborted or retarded ${ }^{19}$. However, in lotus it is unknown whether the low seed-setting rate is caused by self-incompatibility.

This work investigates factors affecting the viability and germination of pollen and self-incompatibility in several lotus cultivars. The basic knowledge gained about pollen viability and self-incompatibility might lead to modifications in lotus breeding programs or changes in lotus cultivation.

\section{MATERIALS AND METHODS}

\section{Natural pollination study}

In this experiment, the study of natural seed setting was carried out using four wild lotus cultivars: Sai Rung (SR) $14^{\circ} 01^{\prime} \mathrm{N}, 100^{\circ} 25^{\prime} \mathrm{E}$, Sam Roi Yot (SY) $12^{\circ} 13^{\prime} \mathrm{N}$, $99^{\circ} 54^{\prime} \mathrm{E}$, Klong Yong (KY) $13^{\circ} 59^{\prime} \mathrm{N}$, $100^{\circ} 23^{\prime} \mathrm{E}$, and Puttha Monthon (PM) $13^{\circ} 47^{\prime} \mathrm{N}, 100^{\circ}$ $20^{\prime} \mathrm{E}$. The four cultivars were grown in a natural lotus field in the central part of Thailand. Mature pods were collected, and the number of pistils and mature seeds counted to determine the seed-setting rate.

\section{Stigma removal and seed setting}

To determine whether the pollen was viable and could germinate a tube to fertilize eggs, an artificial selfpollination experiment was conducted in the SR cultivar. The flowers were divided into four blooming stages: 2 days pre-bloom, 1 day pre-bloom, day 1 of full bloom, and day 2 of full bloom (Fig. 1). Flowers at 2 days pre-bloom were bagged with cheese cloth and were used as maternal parents (six replications). When the maternal plants reached day 1 of the full bloom stage, the flowers were emasculated for hand pollination which took place at 09:00. The pollen donors were chosen from the flowers of day 2 of the full bloom because of the pollen shading. After pollination, the stigmas were excised along with the style at $0,1,3$, and $9 \mathrm{~h}$ (Fig. 2). The cut pistils were allowed to develop into seeds for two weeks and then the developed seeds were counted and classified according to their developmental stage into four (a)

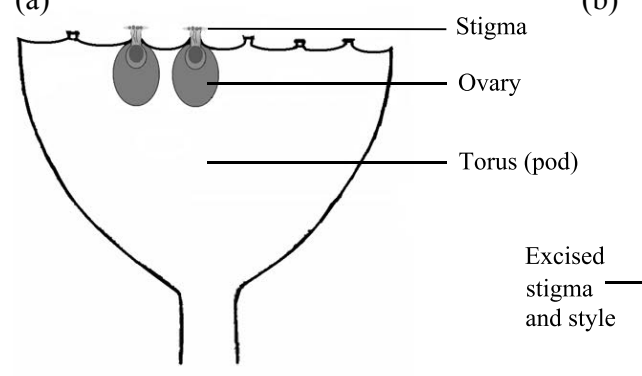

(b)

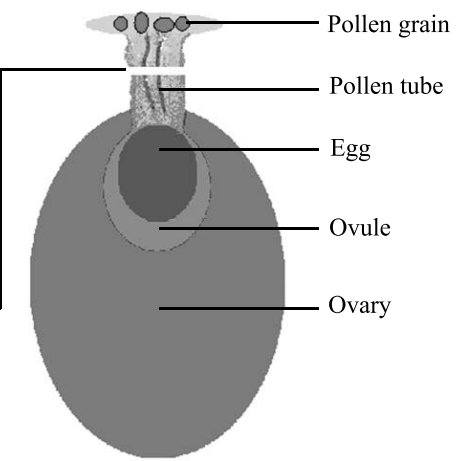

Fig. 2 Schematic diagram showing (a) the torus of lotus and (b) styles were excised after 1, 3, and $9 \mathrm{~h}$ of hand pollination. 
subcategories: fully developed, stunted, aborted, and unfertilized.

\section{Pollen viability at different blooming stages}

To determine the viability of pollen at four different stages of blooming, the PM cultivar was chosen as maternal and paternal parents for self-pollination (Fig. 1). As maternal parents, the flowers of 2 days pre-bloom were bagged before artificial pollination. As the paternal parent, the PM pollen was gathered 2 days later from four different blooming stages at 09:00 and were used immediately for artificial pollination.

The pollen samples were stained with $0.01 \%$ fluorescein diacetate (FDA) in acetone ${ }^{20}$. The stained pollen was observed under a fluorescence microscope (Zeiss Axioskop mc80, Germany). The number of pollen grains was randomly counted from three objective fields under the microscope and the number of viable grains was compared to the total count. Viable pollen grains were observed as bright green fluorescence ${ }^{21}$. The remaining pollen samples were pollinated to the flowers of day 1 of the full bloom. Thirty flowers were used for each treatment. Two weeks after pollination, pods were collected and the developed seeds were counted.

\section{Pollen germination between self- and cross-pollination in vivo}

To compare pollen germination between self- and cross-pollination, two wild cultivars of red-flowered lotus were used in this study: Rachine (RC) and Nakhon Sawan (NW), which were naturally grown at $12^{\circ} 57^{\prime} \mathrm{N}, 99^{\circ} 58^{\prime} \mathrm{E}$ and $15^{\circ} 42^{\prime} \mathrm{N}, 100^{\circ} 10^{\prime} \mathrm{E}$, respectively. These two cultivars were collected and planted at Rajamangala University of Technology, Pathum Thani, Thailand. They were used mainly as a source of lotus seed by local farmers. RC was used as maternal and paternal parents for self-pollination. For cross-pollination, $\mathrm{RC}$ was used as the maternal parent and NW was used as the paternal parent, and vice versa. Flowers of day 1 of the full bloom were used as maternal parents and flowers of day 2 of the full bloom were used as paternal parents.

The maternal flowers of 2 days pre-bloom were covered with cheese cloth bags to prevent natural cross-pollination ${ }^{3}$. On the next 2 days (as day 1 of the full bloom), these maternal flowers were emasculated and pollinated with pollen from the paternal parents. Thirty stigmas were taken from six flowers to observe pollen germination. They were fixed in $70 \%$ FAA solution and stained with $0.01 \%$ aniline blue dye to identify pollen tube germination under a fluorescent microscope (Zeiss, Axioskop mc80, Germany). The pollen grains visible in three random objective fields under the microscope were counted and the number of germinated grains was compared to the total count. The walls of the pollen tubes contain callose ${ }^{22}$ which selectively takes up aniline and emits a bright yellowgreen light $^{23}$ as the outline of the pollen tubes. The non-germinated grains were slightly stained.

\section{Self-incompatibility test}

To compare seed setting between self- and cross-pollination, different cross combinations were used: $\mathrm{RC}$ (o) $\times \mathrm{RC}\left(\sigma^{7}\right), \mathrm{RC}\left(\right.$ (o) $\times \mathrm{NW}\left(0^{7}\right), \mathrm{NW}\left(\right.$ (q) $\times \mathrm{NW}\left(\sigma^{7}\right)$, and NW $(\varphi) \times \mathrm{RC}\left(\sigma^{\top}\right)$. For each combination, thirty flowers were used as maternal plants. After pollination, the flowers were allowed to develop seeds. In the field, open pollination (OP) flowers were allowed to pollinate naturally. The index of self-incompatibility (ISI) was calculated using the formula documented by Horsley and Johnson ${ }^{24}$ : ISI $=100\left(V_{\mathrm{c}}-V_{\mathrm{s}}\right) / V_{\mathrm{c}}$, where $V_{\mathrm{s}}$ and $V_{\mathrm{c}}$ are the number of seed setting per flower from self- and cross-pollination, respectively. The differences between the seed-setting rate per flower in self- and cross-pollination combinations were analysed using Student's $t$-test.

\section{Statistical analysis}

For natural pollination study, the experiment was arranged in a completely randomized design with 4 treatments (cultivars), i.e., KY, PM, SY, and SR. There were $8,9,11$, and 23 replications for treatments 1 , 2,3 , and 4, respectively. ANOVA was conducted using IRRISTAT (version 4.3). Student's $t$-test was calculated based on unequal sample sizes and unequal variances.

\section{RESULTS}

\section{Natural pollination}

In nature, the seed-setting rate of the four sacred lotus cultivars ranged from $(52 \pm 16) \%$ to $(78 \pm 22) \%$ (Table 1). When compared to the PM and SY cultivars, SR and KY produced the lowest and highest percentage of seed setting, respectively. Notably, only half of the number of pistils of SR developed into mature seeds.

\section{Stigma removal and seed setting}

The difference in the seed-setting rate after stigma removal at different times is shown in Fig. 3. In the first hour after stigma removal, the seed-setting rate was about $35 \%$ and reached the maximum rate of seed setting (53\%) at three hours after self-pollination. 
Table 1 Seed-setting rate per total number of pistils of lotus cultivars grown naturally in different areas (mean \pm SD).

\begin{tabular}{lcc}
\hline Cultivar & Number of pods & Seed-setting rate $(\%)^{*}$ \\
\hline Sai Rung & 23 & $52 \pm 16^{\mathrm{b}}$ \\
Sam Roi Yot & 11 & $66 \pm 22^{\mathrm{a}}$ \\
Klong Yong & 8 & $78 \pm 22^{\mathrm{a}}$ \\
Puttha Monthon & 9 & $72.3 \pm 7.0^{\mathrm{a}}$ \\
\hline
\end{tabular}

* Values followed by a different letter are significantly different; $p<0.01$ (Duncan's New Multiple Range Test).

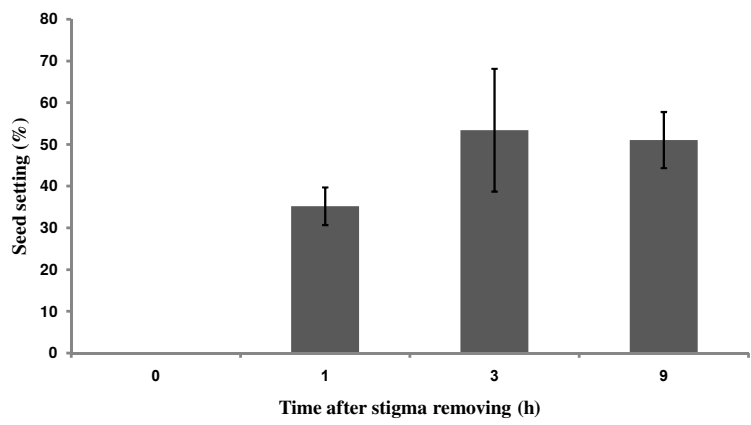

Fig. 3 Percentage of seed setting of SR flowers pollinated with self pollen and then stigmas were excised at different times. Even though the stigmas were excised after the first hour, fertilization was partially completed indicating that the pollen was viable and could germinate and fertilize eggs. The error bars indicate standard deviation from the mean values.

\section{Pollen viability at different blooming stages}

Fig. $4 \mathrm{~b}$ shows that the pollen from flowers of day 2 of full bloom gave the highest seed-setting rate after being pollinated on day 1 of the full bloom. It was clear that at this stage, the pollen was fully developed and was ready to fertilize an egg. There was however seed setting after pollination with the pollen from the 2 day and 1 day pre-bloom flowers indicating that these pollen grains were able to fertilize eggs.

The pollen gathered from different blooming stages of flowers was self-pollinated onto the stigmas and observed for viability (Fig. 4a). The pollen grains from un-bloomed ( 2 days pre-bloom and 1 day prebloom) and bloomed (day 1 of the full bloom and day 2 of the full bloom) flowers were viable based on the FDA staining. However, the viability percentage of the pollen from flowers of day 2 of the full bloom was higher than that of the pollen from other stages of blooming. Seed setting did not correlate with pollen viability (Fig. 5).

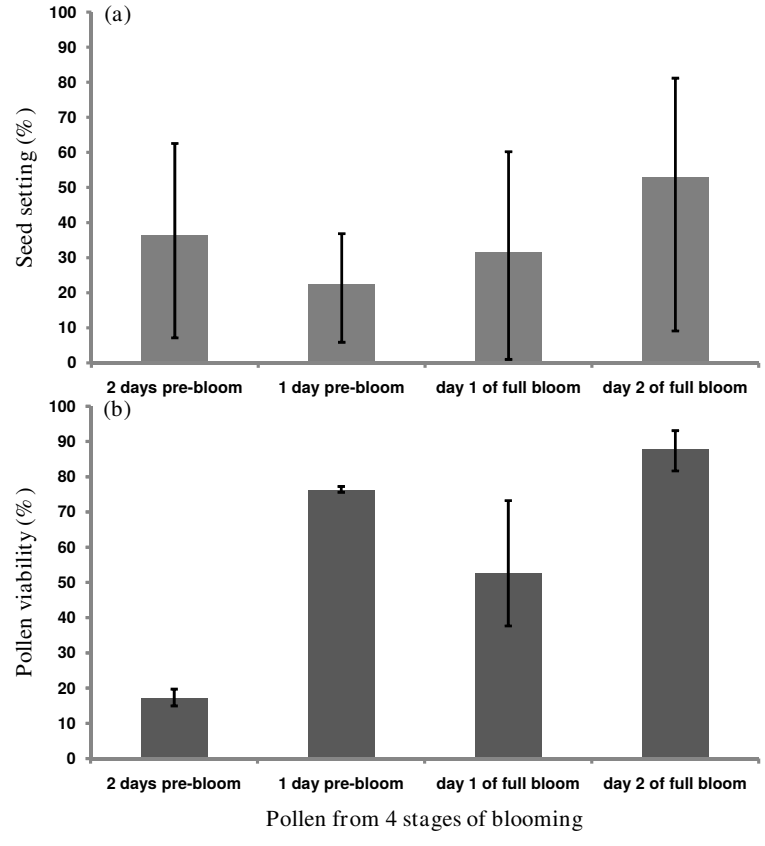

Fig. 4 (a) Percentage of seed setting and (b) pollen viability on day 1 blooming flowers (as maternal parents) using pollen from blooming stages at 2 days pre-bloom, 1 day pre-bloom, day 1 of full bloom and day 2 of full bloom. The results show that pollen grains from the 4 stages of flowering are able to fertilize eggs. Bars indicate the percentile difference between 25 and $75 \%$.

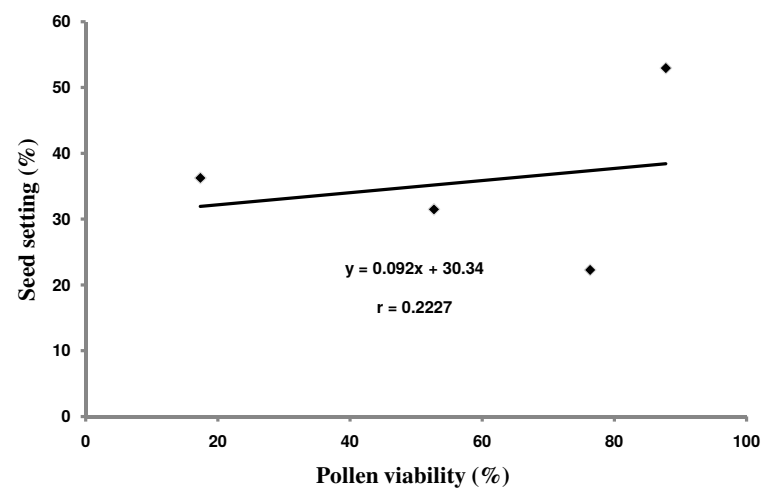

Fig. 5 Correlation between pollen viability and seed setting of hand self-pollinated PM flowers indicating that the seed setting did not relate to the increase in pollen viability. The correlation coefficient $(r)$ indicates that there is no relationship between pollen viability and seed setting.

\section{Pollen germination between self- and cross-pollination in vivo}

Pollen germination on the stigma surface is shown in Fig. 6. A considerable number of pollen grains 


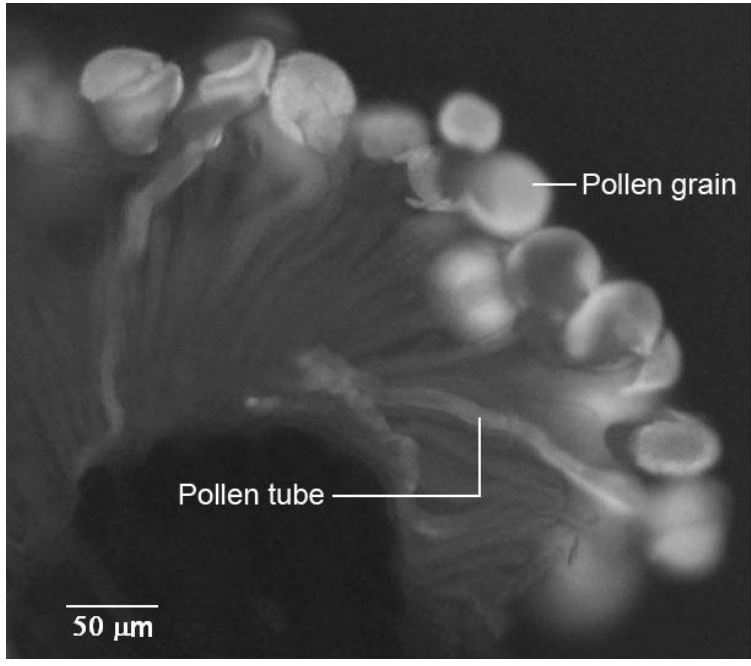

Fig. 6 Germinated pollen grains were stained with $0.01 \%$ aniline blue on the stigma surface and viewed under a fluorescence microscope.

germinated and their tubes had entered the style. The rate of pollen germination on the stigma of the selfpollinated RC flowers was significantly lower $(<1 \%)$ than the rate of germination of cross pollen from NW $(\mathrm{p}<0.05)$ (Fig. 7). In both self- and cross-pollinations, the germination rate reached the maximum at two to three hours after pollination.

\section{Self-incompatibility test}

The index of self-incompatibility was calculated based on the seed-setting rate of self- and cross-pollination. This index showed that the RC and the NW cultivars were highly self-incompatible $(p<0.01)$. These two cultivars produced a low seed-setting rate after selfpollination of 2.8 and $2 \%$, respectively (Table 2 ). The seed-setting rate after two weeks of self-pollination is shown in Table 3. Among 97\% of the undeveloped pistils in RC, $56 \%$ of the seeds aborted (Fig. 8).

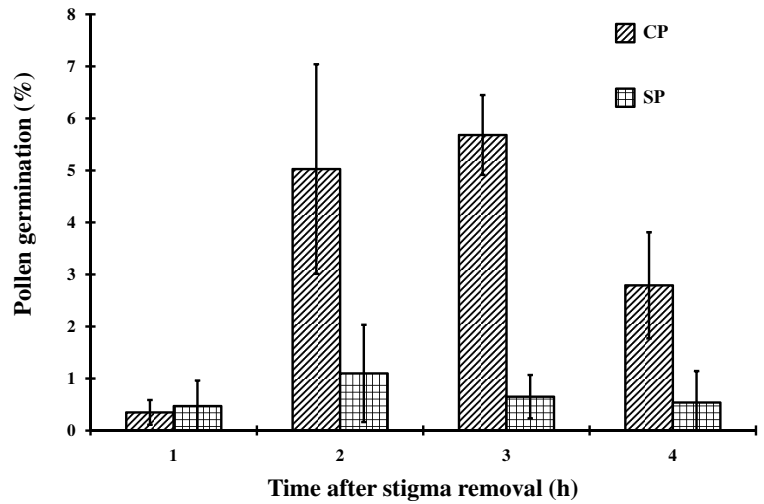

Fig. 7 Percentage of pollen germination on RC stigmas (q) after self-pollination and cross-pollination with $\mathrm{NW}\left(\sigma^{7}\right)$. The cross-pollination increased the percentage of pollen germination within 2 and $3 \mathrm{~h}$ after pollination. The error bars indicate standard deviation from the mean values.

Table 3 Percentage of four seed types from two-week-old pods of RC after self-pollination.

\begin{tabular}{lc}
\hline Seed type & seed setting $(\%)$ \\
\hline Fully developed & 2.8 \\
Undeveloped & 97.2 \\
Unfertilized & 33.6 \\
Aborted & 56.3 \\
Retarded & 7.3 \\
\hline
\end{tabular}

\section{DISCUSSION}

\section{Natural pollination study}

In this study, the seed-setting rate of the sacred lotus varied from $52-78 \%$ under natural conditions, unlike a previous report which gave a seed-setting rate up to $90 \%{ }^{3}$. The lotus seed-setting rate markedly varied among cultivars ${ }^{3,4}$. Many researchers have indicated that the low seed setting in other plants is caused by insufficient pollinators; i.e., pochote

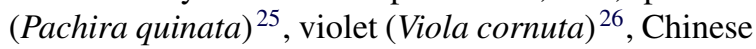
plums (Prunus salicina) ${ }^{27}$, and lotus (N. nucifera) ${ }^{3}$.

Table 2 The self-incompatibility index in RC and NW comparisons of the mean numbers of seed per flower from self- and cross-pollination.

\begin{tabular}{lcccccccc}
\hline Cultivars & \multicolumn{3}{c}{ Flowers pollinated } & \multicolumn{3}{c}{ Seed-setting rate (\%) } & \multirow{2}{*}{-test } & ISI (\%) \\
& SP & CP & OP & SP & CP & OP & & \\
\hline RC (q) & 30 & 30 & 100 & 2.8 & 69.2 & 43.4 & $* *$ & 96.0 \\
NW (q) & 30 & 30 & 100 & 2.3 & 50.8 & 61.6 & $* *$ & 95.5 \\
\hline
\end{tabular}

$\mathrm{RC}\left(\sigma^{7}\right)$ crossed with NW (ㅇ) and NW ( $\sigma^{7}+$ ) crossed with RC (ㅇ); SP = self-pollination; $\mathrm{CP}=$ cross-pollination; $\mathrm{OP}=$ open pollination; $* *=$ significant difference in seed-setting rate between self- and cross-pollination; $p<0.01$ (Student's $t$-test). 


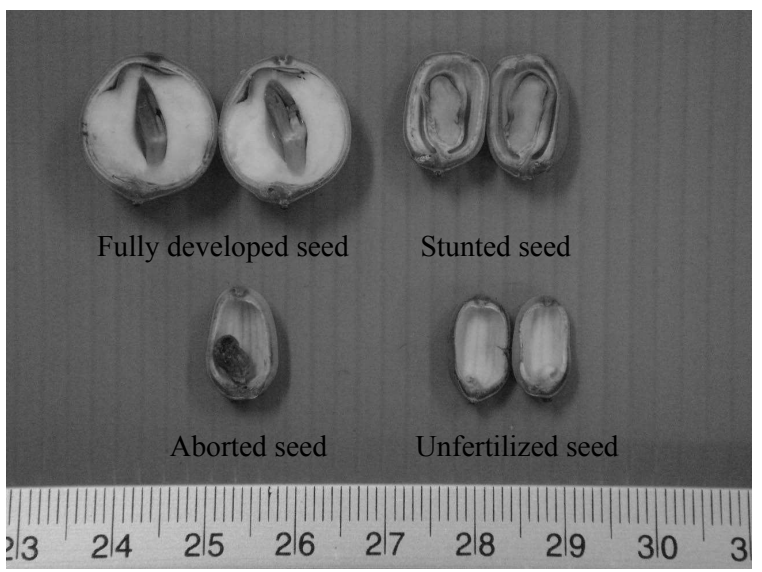

Fig. 8 Four types of two-week-old seeds of lotus after selfpollination: fully developed seed, stunted seed, aborted seed and unfertilized seed. The unit is $\mathrm{cm}$ for the scale.

Either insufficient or ineffective pollinators lower the number of pollen grains on the stigma ${ }^{16,26}$. Seed set is limited by the pollen shortage ${ }^{28}$. A low number of pollen grains on stigma limits the seed-setting rate ${ }^{25,29}$ because it reduces the chance for a pollen tube to fertilize an $\operatorname{egg}^{26}$, especially in open pollination $^{27}$. It was reported that lotus cultivars with a high seed-setting rate were observed in regions where pollinators were abundant ${ }^{3}$.

However, the current study showed a contrasting result. Although the four cultivars were naturally grown in places where Apis sp. and Trigona sp. were abundantly found, low seed setting was observed. Bees are the most effective pollinator for flowering plants ${ }^{30,31}$. In the current study, bees were plentiful, but the seed-setting rate was never over $78 \%$ (Table 1). This indicates that not only the pollinator was an important criterion for the seed-setting rate in lotus, but also the interaction between pollen and pistil could affect pollen germination and fertilization. Since there was abundance of pollinators in the study areas, the seed-setting rate was unlikely to be limited by pollinators.

\section{Stigma removal and seed setting}

Approximately 35, 53, and 51\% of the pistils developed into seeds even if the stigmas were cut within 1, 3, and $9 \mathrm{~h}$ after pollination, respectively (Fig. 3). This indicated that there should be numerous viable pollen grains that could germinate the tubes to fertilize eggs. Nevertheless, not all pistils developed into seeds indicating that self-incompatibility might exist and affects the fertilization leading to the low number of seed setting. The seed-setting rate could be an indicator to predict fertilization efficiency ${ }^{4,9,11}$.

\section{Pollen viability at different blooming stages}

In this study, the pollen viability from the 2 day prebloom flowers was very low $(20 \%)$, indicating that most pollen was immature. The low viability of the pollen resulted in a low level of seed setting (35\%). The viability of pollen from the day 1 and day 2 full bloom flowers increased and led to an increase in seed setting (Fig. 4). Similar results were found in studies of pollen viability and seed set in sorghum ${ }^{32}$, strawberry ${ }^{33}$, and lotus ${ }^{4,9}$.

Notably, the pollen of day 2 full bloom was fully developed ( $88 \%$ viability) because it was in the shading stage of pollen under natural conditions, resulting in an increased seed setting rate (53\%). It is likely that most pollen had the ability to germinate and invade through the style and reach the ovary. This result is similar to a cross-pollination study which illustrated that the viability of pollen was around $20 \%$ but could increase seed setting up to $18 \%^{4,9}$.

\section{Pollen germination between self- and cross-pollination in vivo}

Pollen germination rate increased at $2-3 \mathrm{~h}$ after pollination. The cross-pollinated stigma allowed better pollen germination than self-pollinated stigma. NW cross pollen could therefore germinate at a significantly higher rate than the RC self pollen $(p<0.05)$ (Fig. 7). This result indicates that in lotus a low seed setting rate is related to self-incompatibility. Wang et $\mathrm{al}^{4}$ and Teng et $\mathrm{al}^{9}$ however showed that the maximum number of germinated pollen of jinsenianhua $\times$ qinhuaihuadeng, and qinhuaihuadeng $\times$ jinsenianhua lotus was highest at $4 \mathrm{~h}$ after pollination. Self-pollinated plants with a low pollen germination rate have been reported in other plants ${ }^{27,34,35}$. In Chaenomeles japonica self pollen deterioration occurs and the pollen tubes stunt at 3 days after pollination, whereas the cross pollen is able to grow rapidly into the style. In the self pollen case, the germinated tube arrest in the style, while the cross pollen is able to grow successfully in the style ${ }^{35}$.

\section{Self-incompatibility test}

The results of artificial pollination revealed that there was self-incompatibility in RC and NW cultivars. Both RC and NW showed similar self-incompatibility (Table 2). The seed-setting rate in both cultivars was higher after cross-pollination than in self-pollination indicating that seed setting was limited by self-pollination. For the SR and the PM cultivars, seed setting by self-pollination was rather high (around 40\%) 
(Fig. 3 and Fig. 4b, respectively) which indicated that self-incompatibility did not have the same intensity in other cultivars of lotus compare to NW and RC. The result was similar to that of Mansur et $\mathrm{al}^{36}$ who studied self-incompatibility in Huilli (Leucocoryne sp.).

Lotus has a protogynous flower where its stigma receptivity is one day earlier than the shading of the anthers. Protogyny and protandry often co-exist with self-incompatibility to prevent self-gamete fertilization $^{10,12}$. Self-incompatibility occurs commonly in many flowering plant species ${ }^{36}$. The degree of self-incompatibility is illustrated by the index of self-incompatibility ${ }^{24}$. Normally, in self-incompatible and selfcompatible plants, the index of self-incompatibility is greater than $80 \%$ and less than $50 \%$, respectively ${ }^{37}$. In self-incompatible plants, self-pollination lowered the seed-setting rate ${ }^{16}$ whereas cross-pollinated plants gave a higher fruit setting rate ${ }^{35,36,38,39}$. Manual selfpollination did not increase the seed-setting rate due to inbreeding depression ${ }^{36,39,40}$. Self-incompatibility in Crape myrtle (Lagerstroemia spp.), inhibits pollen tube elongation and fruit set ${ }^{41}$. Cross-pollinated flowers of Bulnesia give a more than 35-fold higher seed-setting rate than self-pollinated flowers ${ }^{39}$. Crosspollination increases the rate of fertilization in $\mathrm{Pseu}$ dowintera asillaris ${ }^{42}$. However, self-incompatibility partially limits seed set in Flourensia cernua ${ }^{11}$.

In the current study, low seed setting was found under natural conditions. The result is similar to the artificial self pollination study which showed that the pollen viability and pollen germination ability were high, but the seed-setting rate never exceeded 53\% (Fig. 4b). Possibly, self-incompatibility inhibited the growth of the pollen tube in the style and prevented pollen nuclei from fertilizing the eggs ${ }^{43}$. This selfincompatibility lead to a low seed-setting rate. The delay in pollination increased the abortion rate of self-seed setting ${ }^{44}$. The presence of $56 \%$ aborted seed (Table 3 and Fig. 8) indicated that some postembryonic suppression existed and this could affect the seed-setting rate. Embryo abortion has also been reported in another study of lotus ${ }^{4}$. Seed abortion was also obtained in self-pollination of Silene vulgaris ${ }^{15}$ and in Capparis $^{45}$.

\section{CONCLUSIONS}

Pollen from un-bloomed flowers can be used for fertilization. Both of the day 1 and day 2 full bloom flowers were suitable to use as maternal parents. The study of pollen viability and germination indicated that the low seed-setting rate was involved with selfincompatibility of lotus. Moreover, the results show that self-incompatibility did not exist in all lotus cultivars.

The basic knowledge gained from this study is useful for breeding programmes of lotus. From the study it was found that pollen from un-bloomed flowers can be used for fertilization and the time required to achieve seed setting is $3 \mathrm{~h}$. The $\mathrm{RC}$ and NW wild cultivars, with each having a high index of self-incompatibility, are not suitable to be grown as a single cultivar. To increase cross-pollination and seed setting, the different cultivars must be grown in contiguous areas.

Acknowledgements: The authors would like to thank the Kasetsart University Research and Development Institute (KURDI), the Graduate School of Kasetsart University and the Higher Education Research Promotion and National Research University Project of Thailand, Office of the Higher Education Commission for financial support to carry out the project.

\section{REFERENCES}

1. Mukherjee PK, Balasubramanian R, Saha K, Saha BP, Pal M (1996) A review on Nelumbo nucifera Gaertn. Ancient Sci Life 15, 268-76.

2. Tian D, Tilt KM, Sibley JL, Woods FM, Dane F (2009) Response of lotus (Nelumbo nucifera Gaertn.) to planting time and disbudding. Hortscience 44, 656-9.

3. Li JK, Huang SQ (2009) Effective pollinators of Asian sacred lotus (Nelumbo nucifera): contemporary pollinators may not reflect the historical pollination syndrome. Ann Bot 104, 845-51.

4. Wang YL, Guan ZY, Chen FD, Fang WM, Teng NJ (2012) Pollen viability, pistil receptivity and embryo development in hybridization of Nelumbo nucifera Gaertn. Sci World J 2012, ID 678706.

5. Ramirez N, Berry PE (1997) Effect of sexual systems and dichogamy on levels of abortion and biomass allocation in plant reproductive structures. Can J Bot 75, 457-61.

6. Kim DY, Yoon MK, Do KR, Kim TI (2009) Effects of pollen viability and pistil receptivity on seed set for artificial pollination in strawberry. Kor J Breed Sci 41, 496-501 (in Korean).

7. Wang ZY, Ge YX, Scott M, Spangenberg G (2004) Viability and longevity of pollen from transgenic and nontransgenic tall fescue (Festuca arundinacea) (Poaceae) plants. Am J Bot 91, 523-30.

8. Dafni A, Firmage D (2000) Pollen viability and longevity: Practical, ecological and evolutionary implications. Plant Systemat Evol 222, 113-32.

9. Teng NJ, Wang YL, Sun CQ, Fang WM, Chen FD (2012) Factors influencing fecundity in experimental crosses of water lotus (Nelumbo nucifera Gaertn.) cultivars. BMC Plant Biol 12, 82. 
10. Ramsey M, Vaughton G (2000) Pollen quality limits seed set in Burchardia umbellata (Colchicaceae). Am J Bot 87, 845-52.

11. Ferrer MM, Good-Avila SV, Montaña C, Domínguez CA, Eguiarte LE (2009) Effect of variation in selfincompatibility on pollen limitation and inbreeding depression in Flourensia cernua (Asteraceae) scrubs of contrasting density. Ann Bot 103, 1077-89.

12. Ramsey M, Vaughton G (1991) Self-incompatibility, protandry, pollen production and pollen longevity in Banksia menziesii. Aust J Bot 39, 497-504.

13. Ellis ME, Sedgley M (1992) Floral morphology and breeding system of three species of Eucalyptus, section Bisectaria (Myrtaceae). Aust J Bot 40, 249-62.

14. Boutley MB, Husband BC (2003) The effect of protandry on siring success in Chamerion angustifolium (Onagraceae) with different inflorescence sizes. Evolution 57, 240-8.

15. Glaettli M (2004) Mechanisms involved in the maintenance of inbreeding depression in gynodioecious Silene vulgaris (Caryophyllaceae): an experimental investigation. $\mathrm{PhD}$ thesis, Université de Lausanne.

16. Li HL, An SQ, Zhi YB, Yan C, Zhao L, Zhou CF, Deng ZF, Su W, et al (2008) Protogynous, pollen limitation and low seed production reasoned for the dieback of Spartina anglica in coastal China. Plant Sci 174, 299-309.

17. Nuortila C, Tuomi J, Aspi J, Laine K (2006) Earlyacting inbreeding depression in a clonal dwarf shrub, Vaccinium myrtillus, in a northern boreal forest. Ann Bot Fenn 43, 36-48.

18. Goodwillie C (1997) The genetic control of self-incompatibility in Linanthus parviflorus (Polemoniaceae). Hereditas 79, 424-32.

19. Korkutal I (2005) Embryo abortion in some new seedless table grape (Vitis vinifera L.) varieties. Int J Bot $\mathbf{1}$, $1-4$.

20. Sedgley M, Harbard J (1993) Pollen storage and breeding system in relation to controlled pollination of four species of Acacia (Leguminosae: Mimosoideae). Aust J Bot 41, 601-9.

21. Girijashankar V (2010) Effect of Eucalyptus pollen isolation methods on pollen viability, debris content, quantity isolated and pollen density per stigma. J Plant Breed Crop Sci 2, 273-9.

22. Parre E, Geitmann A (2005) More than a leak sealant: The mechanical properties of callose in pollen tubes. Plant Physiol 137, 274-86.

23. Yim KO, Bradford KJ (1998) Callose deposition is responsible for apoplastic semipermeability of the endosperm envelope of Muskmelon seeds. Plant Physiol 118, 83-90.

24. Horsley TN, Johnson SD (2007) Is Eucalyptus cryptically self-incompatible? Ann Bot 100, 1373-8.

25. Quesada M, Fuchs EJ, Lobo JA (2001) Pollen load size, reproductive success, and progeny kinship of naturally pollinated flowers of the tropical dry forest tree Pachira quinata (Bombacaceae). Am J Bot 88, 2113-8.

26. Miyajima D (2006) Pollination and seed production in Viola. Hortscience 41, 633-9.

27. Jia HJ, He FJ, Xiong CZ, Zhu FR, Okamoto G (2008) Influences of cross pollination on pollen tube growth and fruit set in Zuili plums (Prunus salicina). J Integr Plant Biol 50, 203-9.

28. Hirayama K, Ishida K, Tomaru N (2005) Effects of pollen shortage and self-pollination on seed production of an endangered tree, Magnolia stellata. Ann Bot 95, 1009-15.

29. Kalinganire A, Harwood CE, Slee MU, Simons AJ (2000) Floral structure, stigma receptivity and pollen viability in relation to protandry and self-incompatibility in silky oak (Grevillea robusta A. Cunn.). Ann Bot 86, 133-48.

30. Seymour RS, Schultze-Motel P (1998) Physiological temperature regulation by flowers of the sacred lotus. Phil Trans Roy Soc Lond B 353, 935-43.

31. Heard TA (1999) The role of stingless bees in crop pollination. Annu Rev Entomol 44, 183-206.

32. Lansac AR, Sullivan CY, Johnson BE, Lee KW (1994) Viability and germination of the pollen of sorghum [Sorghum bicolor (L.) Moench]. Ann Bot 74, 27-33.

33. Kaczmarska E, Dobrowolska AM, Hortyński JA (2008) The influence of pollen viability on seed set and fruit mass in strawberry (Fragaria $\times$ ananassa Duch.). Acta Agrobot 61, 79-84.

34. Kalla SE, Ashman TL (2002) The effects of pollen competition on progeny vigor in Fragaria virginiana (Rosaceae) depend on progeny growth environment. Int J Plant Sci 163, 335-40.

35. Kaufmane E, Rumpunen K (2002) Pollination, pollen tube growth and fertilization in Chaenomeles japonica (Japanese quince). Sci Hort 94, 257-71.

36. Mansur L, Gonzalez M, Rojas I, Salas P (2004) Selfincompatibility in the Chilean endemic genus Leucocoryne Lindley. J Am Soc Hort Sci 129, 836-8.

37. Pound LM, Wallwork MAB, Potts BM, Sedgley M (2002) Early ovule development following self- and cross- pollinations in Eucalyptus globulus Labill. ssp. globulus. Ann Bot 89, 613-20.

38. Müller N, Schneller JJ, Holderegger R (2000) Variation in breeding system among populations of the common woodland herb Anemone nemorosa (Ranunculaceae). Plant Systemat Evol 221, 69-76.

39. Debandi G, Rossi B, Araníbar J, Ambrosetti JA, Peralta IE (2002) Breeding system of Bulnesia retama (Gillies ex Hook \& Arn.) Gris. (Zygophyllaceac) in the central Monte desert (Mendoza, Argentina). J Arid Environ 51, 141-52.

40. Paulino-Neto HF (2007) Pollination and breeding system of Couepia uiti (Mart. and Zucc.) Benth (Chrysobalanaceae) in the Pantanal da Nhecolândia. Braz J Biol 67, 715-9.

41. Pounders C, Reed S, Pooler M (2006) Comparison of self- and cross-pollination on pollen tube growth, 
seed development, and germination in Crapemyrtle. Hortscience 41, 575-8.

42. Sage TL, Sampson FB (2003) Evidence for ovarian self-incompatibility as a cause of self-sterility in relictual woody angiosperm, Pseudowintera asillaris (Winteraceae). Ann Bot 91, 807-16.

43. Valtueña FJ, Rodríguez-Riaño T, Espinosa F, OrtegaOlivencia A (2010) Self-sterility in two Cytisus species (Leguminosae, Papilionoideae) due to early-acting inbreeding depression. Am J Bot 97, 123-35.

44. Levri MA (1998) The effect of timing of pollination on the mating system and fitness of Kalmia latifolia (Ericaceae). Am J Bot 85, 1626-30.

45. Primo LM, Machado IC (2009) A new case of lateacting self-incompatibility in Capparis L. (Brassicaceae): C. jacobinae Moric. ex Eichler, an endemic andromonoecious species of the Caatinga, Pernambuco State, Brazil. Acta Bot Bras 23, 764-8. 